\title{
Edward Jenner and the small pox vaccine
}

\author{
Kendall A. Smith* \\ Division of Immunology, Department of Medicine, Weill Medical College of Cornell University, New York, NY, USA
}

\section{Edited by:}

Blossom Damania, University of North Carolina at Chapel Hill, USA

Reviewed by:

Dirk Dittmer, University of North Carolina at Chapel Hill, USA

Klaus Früh, Oregon Health \& Science

University, USA

Christian Engwerda, Queensland

Institute of Medical Research,

Australia

*Correspondence:

Kendall A. Smith, Division of Immunology, Department of

Medicine, Weill Medical College of Cornell University, 407 East 61st

Street, New York, NY 10065, USA.

e-mail: kasmith@med.cornell.edu
Edward Jenner, who discovered that it is possible to vaccinate against Small Pox using material from Cow Pox, is rightly the man who started the science of immunology. However, over the passage of time many of the details surrounding his astounding discovery have been lost or forgotten. Also, the environment within which Jenner worked as a physician in the countryside, and the state of the art of medicine and society are difficult to appreciate today. It is important to recall that people were still being bled at the time, to relieve the presence of evil humors. Accordingly, this review details Jenner's discovery and attempts to place it in historical context. Also, the vaccine that Jenner used, which decreased the prevalence of Small Pox worldwide in his own time, and later was used to eradicate Small Pox altogether, is discussed in light of recent data.

Keywords: Small Pox, vaccination, Cow Pox, vaccinia
Somewhere in my immunological training I learned that Edward Jenner, a simple country doctor from Gloucestershire, discovered that it was possible to protect against the dread disease Small Pox by injecting material taken from a similar pox disease of cows. Then, as the story goes, soon after his publication (Jenner, 1798), the Queen had her children vaccinated, which led to an immediate acceptance of the practice, and Parliament voted to recognize Jenner by granting him a life-time pension. Then to top it all, King George III Knighted Jenner, and he lived happily ever after.

Essentially the only true part of this story relates to Jenner's discovery of vaccination against Small Pox using Cow Pox. The rest is all far from what really happened.

In the eighteenth century, Small Pox was a dread disease, accounting for about $10 \%$ of all deaths. It was especially virulent in infants and children, and when it swept through a village, from 20 to $50 \%$ of those infected died as a consequence. Moreover, those who survived were often disfigured from pockmarks, and smallpox led to blindness when it spread to the eyes.

Around 1720, Lady Mary Wortley Montegue, the wife of the British Ambassador to Turkey, returned to England enthusiastic about Small Pox inoculation, a practice she had learned of in Constantinople (Saunders, 1982). At the time, it was well known that survivors of Small Pox were exempt from the disease during subsequent epidemics. As a consequence, in Asia, protection from Small Pox was commonly attempted by intranasal inhalation of pox material. During a Small Pox epidemic in London in 1721, Lady Montegue had her 4-year-old daughter inoculated with pox material. Subsequently, throughout the eighteenth century, the practice, known as variolation, or simply inoculation, became commonplace throughout the United Kingdom (Saunders, 1982).

Variolation held that it was possible to protect against the very high mortality resulting from a natural infection, which usually occurred by the inhalation of a large dose of virus, by the well-controlled inoculation of a smaller dose of the virus into the skin. Physicians became expert in the practice, and set up special inoculation infirmaries to support and care for those who became ill after inoculation. Although it was common for the inoculated to become symptomatic, and some actually succumbed, the mortality rates advertised by the most expert physicians were as low as $1 \%$. As such, variolation became a very lucrative practice for British doctors, especially during epidemics, when the populace was terribly frightened. However, variolation also ensured that the disease would be endemic and never disappear from the communities.

Edward Jenner was born in 1749 in the UK western county of Gloucestershire. Unfortunately he lost both his mother and father as a young child, and was raised by his older brother (Saunders, 1982). As a consequence of the family's reduced financial circumstances, he did not attend university at Oxford to be trained for the clergy as was customary for his family, but instead he was apprenticed to a local physician at the age of 13 . He proved to be an excellent student, and after 6 years, he was sent to St. Georges Hospital in London, where he was taken in by John Hunter, who was to become one of the world's most famous surgeons. While he was with Hunter he met and became friends with Joseph Banks, who in 1771 had just returned as the naturalist on Captain Cook's first around the world voyage. On the recommendation of Hunter, Jenner helped Banks in the arrangement and cataloging of the specimens from the voyage. Banks went on to an illustrious career, and became the President of the Royal Society for more than 40 years. Thus, early in his career, Jenner entered into an exceptional community of scientists and physicians of his generation.

Toward the end of his training at St. Georges, Hunter offered Jenner a post as his assistant for his teaching and dissecting efforts at the Hospital. However, Jenner declined and returned to his hometown, Berkley, a small village west of Oxford in dairy country 
and set up a general practice. There, Jenner spent the next 20 years, administering to the people from the surrounding farmlands. He did find time to pursue his studies in natural history (i.e., science), and submitted his studies on the reproductive habits of the cuckoo to the Royal Society, encouraged by the now Sir Joseph Banks, with whom Jenner was in steady correspondence throughout his life (Jenner, 1788). As a consequence, Jenner was elected as a Fellow of the Royal Society at the age of 39, quite an accomplishment for a "simple country doctor."

Like the other physicians of his day, Jenner became expert at variolation. In this regard, it is important to appreciate that variolation had become established and practiced for 50 years when Jenner commenced his practice (Saunders, 1982). While administering to his country clientele, Jenner described in his "The Origin of the Vaccine Inoculation":

I was first excited by observing, that among those whom in the country I was frequently called upon to inoculate, many resisted every effort to give them the Small Pox. These patients I found had undergone a disease they called the Cow Pox, contracted by milking cows affected with a peculiar eruption on their teats. On inquiry, it appeared that this had been known among the dairies immemorial, and a vague opinion prevailed that the Cow Pox was preventative of the Small Pox.......This led me to inquire among medical practitioners in the country around me, who all agreed in the sentiment that the Cow pox was not relied upon as a preventative of the Small Pox.(Jenner, 1801)

Although these considerations from the medical establishment temporarily dissuaded Jenner from following his intuition, he persisted in his thoughts, and collected over the years a wealth of experience from variolating people who had previously contracted the Cow Pox.

After 20 years of general practice, in 1792 Jenner was awarded the MD degree from St. Andrews University, Scotland, upon the recommendation of two of his longtime friends, as well as the payment of a fee, evidently a common practice at the time (Saunders, 1982). Accordingly, now able to advertise himself as a physician and surgeon, MD, FRS, he gave up general practice and became a private consultant. Soon thereafter, Jenner contracted typhus, which led to a long convalescence, and eventually in 1795 his move to Cheltenham, a "spa town" between Berkley and Oxford, where mineral springs had been discovered. Here, Jenner began to mix with the aristocracy, which migrated there from London to "take the waters" during the summer months ("The Season"). Also, he now had time to organize and write-up his experiences with variolation of individuals who had a history of a prior illness due to the Cow Pox.

In Cheltenham, Jenner evidently underwent a "midlife crisis," or at least a metamorphosis. Removed from the small village of Berkley, and surrounded by "London society," Jenner was described as a gregarious gentleman who thrived in his new environment (Saunders, 1982). He played the violin, drew well, and fancied himself as a poet. He kept a good table, was an interesting host, conversant in a variety of subjects, and was well regarded both professionally and socially by a wide range of colleagues and friends, many of whom were very influential, politically, and socially.

In 1796, Jenner submitted a manuscript to the Royal Society, which described the case histories of 13 people who had resisted either variolation or natural Small Pox after having a history of Cow Pox. This manuscript also described Jenner's first vaccination, which will be discussed in detail later. Sir Joseph Banks evidently was not too impressed by the manuscript, as he sent it on to Lord Somerville, President of the Board of Agriculture. Eventually, the manuscript was simply returned without being read to the Royal Society. Such was the appreciation of medicine by the "real scientists" of the time.

Rebuffed by the Royal Society, Jenner extended the manuscript with additional case histories, eventually comprising 25 individuals with a history of having had Cow Pox: he tested 24 and found them to resist variolation. Some of these individuals who appeared immune to Small Pox had had a Cow Pox infection several decades previously, thereby suggesting that the Cow Pox "immunity" was very long lasting. Most important, Jenner added a description of at least nine individuals who were injected with Cow Pox, of whom four he variolated and found to resist Small Pox. With this enhanced manuscript, Jenner arranged to have it published in London at his own expense, thereby circumventing the Royal Society (Jenner, 1798). This represents the first "open access" report published in immunology!

Reading through Jenner's descriptions of his cases, the meticulous detail and the thought and analysis that he employed are quite impressive, even two centuries later. Several points made by Jenner via these case histories are noteworthy. For example, in case number four, he describes a woman who had Cow Pox 31 years prior to variolation in 1791 .

Upon inoculation of Small Pox,

an effervescence of a palish red color soon appeared about the parts where the (variolous) matter was inserted, and spread itself rather extensively, but died away in a few days without producing any variolous symptoms. It is remarkable that variolous matter, when the system is disposed to reject it, should excite inflammation on the part to which it is applied more speedily than when it produces the Small Pox.

Thus, this is perhaps the first description of an anamnestic immune response!

In case six, Jenner states

It is so well known among our Dairy Farmers, that those who have had the Small Pox either escape the Cow Pox, or are disposed to have it slightly. Thus, as soon as the complaint shews itself among the cattle, assistants are procured who have had the Small Pox, and are thus rendered less susceptible of the Cow Pox. Otherwise, the farm could scarcely go forward.

Accordingly, Jenner describes the reciprocal protection afforded by Small Pox and Cow Pox infections.

Jenner's description of his first successful vaccination (Cases 16 and 17) is especially interesting.

Sarah Nelmes, a dairymaid at a farmer's near this place, was infected with the Cow Pox from her master's cows in May, 1796. She received the infection on a part of the hand, which 


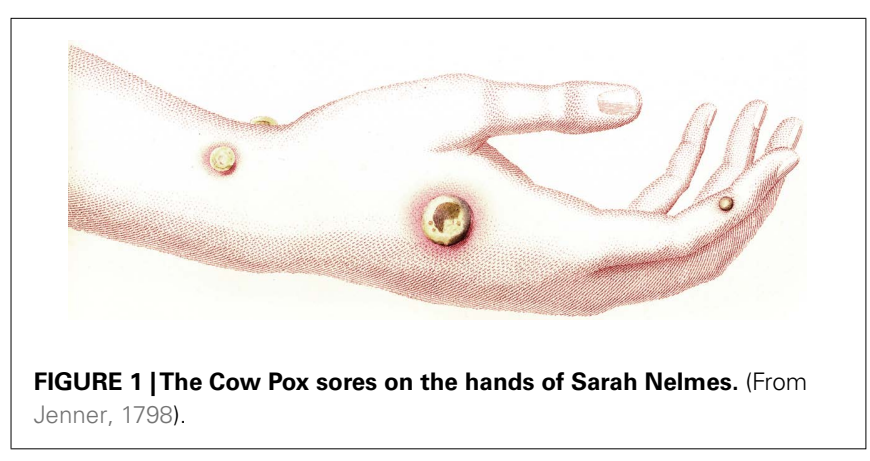

had previously in a slight degree been injured by a scratch from a thorn. A large pustulous sore and the usual symptoms accompanying the disease were produced in consequence. The pustule was so expressive of the true character of the Cow Pox, as it commonly appears on the hand, that I have given a representation of it in the annexed plate. (Figure 1)

The more accurately to observe the progress of the infection, I selected a healthy boy, about eight years old, for the purpose of inoculation for the Cow Pox. The matter was taken from a sore on the hand of a dairymaid (Sarah Nelmes), and it was inserted on the $14^{\text {th }}$ of May, 1796, into the arm of the boy by means of two superficial incisions, barely penetrating the cutis, each about half an inch long.

On the seventh day he complained of uneasiness in the axilla, and on the ninth he became a little chilly, lost his appetite, and had a slight head-ache. During the whole of this day he was perceptively indisposed, and spent the night with some degree of restlessness, but on the day following he was perfectly well.

In order to ascertain whether the boy, after feeling so slight an affection of the system from the Cow-pox virus, was secure from the contagion of the Small Pox, he was inoculated the $1^{\text {st }}$ of July following with variolous matter, immediately taken from a pustule. Several slight punctures and incisions were made on both arms, and the matter was carefully inserted, but no disease followed. ...... Several months afterwards, he was again inoculated with variolous matter, but no sensible effect was produced on the constitution.

Jenner published his An Inquiry into The Causes and Effects of Variolae Vaccinae, a Disease Discovered in some of the Western Counties of England, Particularly Gloucestershire, and Known by the Name of Cow Pox, on June 21st 1798.

Subsequently, Jenner followed-up his original publication with a 1799 "Further Observations on the Variolae Vaccinae," in which he detailed how to recognize typical Cow Pox lesions and to discriminate them from other similar pustular lesions that were not Cow Pox (Jenner, 1799). In this regard, it is important to point out that the causes of all microbial infections, particularly pyogenic bacterial infections that could be confused with Cow Pox pustules, were completely unrecognized in 1798, and did not become known until Robert Koch's description of the bacilli that causes anthrax in 1876, almost 100 years later (Koch, 1876).
In 1800 Jenner continued to educate physicians about vaccination with "A Continuation of Facts and Observations Relative to the Variolae Vaccinae or Cow Pox," in which he chronicled the successes from his physician friends who he had sent Cow Pox material to propagate and to vaccinate individuals in their own communities (Jenner, 1800). Thus, within the early years after his first publication, word of the innocuous nature of vaccination spread fairly rapidly, also making its way to the European continent and to the US. During these years Jenner focused his practice almost entirely on vaccinating all who came to Cheltenham. Consequently, he slowly depleted his savings as the word spread, because he did not charge for the vaccination, especially of the poor.

Not everyone immediately embraced the idea, especially the physicians who had lucrative Small Pox inoculation infirmaries and practices. Thus, as time progressed, the UK became divided into those who ascribed to vaccination and those who were skeptical and thought that only Small Pox inoculation would confer true protection against Small Pox.

Thus, when several of Jenner's Cheltenham acquaintances, who were Members of Parliament, petitioned Parliament to award him a prize for his discovery, there were both supporters as well as dissenters. In 1802 Parliament awarded him $£ 10,000$, which in today's currencies is $\sim \$ 700,000$. However, an award of $£ 20,000$ was defeated by only three votes. This award was crucial for Jenner, in that it allowed him to establish himself in Cheltenham society, and to devote himself to furthering the spread of vaccination all over the world. Then in 1807, after he had been recognized by many foreign governments, Parliament awarded him a second

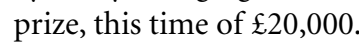

However, despite the fact that vaccination was recognized as a miracle by most of the world, one that saved many lives, the practice of variolation continued in the UK. This practice ensured that Small Pox circulated continuously and intermittently caused epidemics, leading to death, and disfigurement. Moreover, the one thing that would have made a difference in his homeland, i.e., recognition by the Crown, proved elusive. Evidently, those physicians who made their living from variolation held more sway with the King than those who supported Jenner and vaccination. Not until King George III died in 1820, did the new King George IV appoint Edward Jenner Physician Extraordinary to the King on March 16, 1821. However, he was never made a Knight.

Jenner continued to press his case for 25 years after the publication of the Inquiry, facilitating worldwide vaccination by sending seed samples of Cow Pox material to anyone who asked. He died in 1823, at the age of 74. It was not until 1840 that Parliament outlawed the practice of variolation, making Cow Pox vaccination the official UK policy.

As one can imagine, during the entire nineteenth century and the first half of the twentieth century methods were not available to characterize viruses at the molecular and genetic levels. Therefore, the vaccines used all over the world became diverse. Initially, most Cow Pox vaccines were derived via Jenner and his colleagues and passaged arm-to-arm from vaccinees (Baxby, 1981). However, these sources gradually became mixed with other isolates, derived from cows as well as most probably Small Pox isolates passed through animals as well as humans. Toward the end of the nineteenth century, vaccines became produced from calf skin 


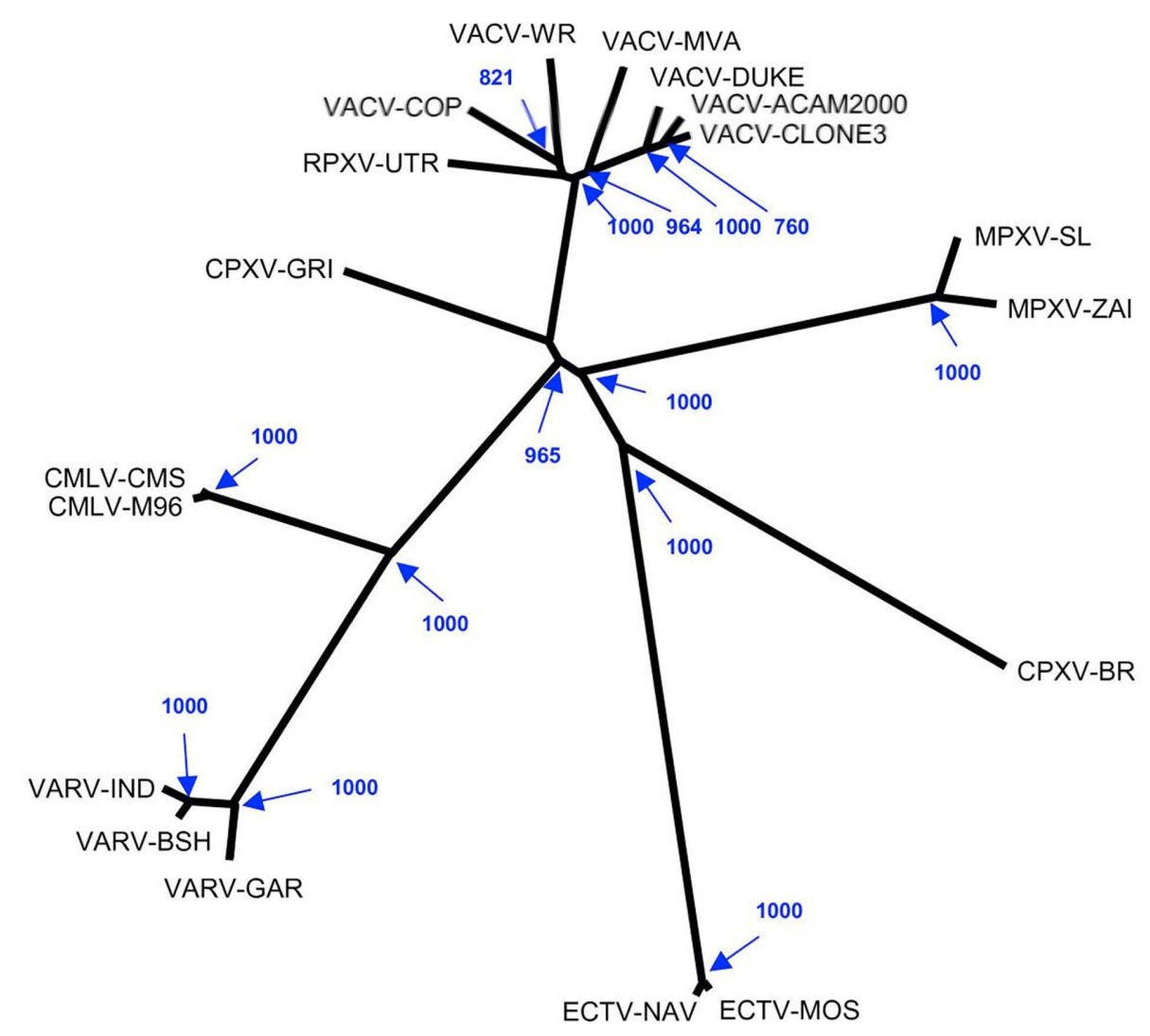

FIGURE 2 | Phylogenetic tree of the orthopox viruses. The tree was generated using an $82 \mathrm{~kb}$ DNA sequence conserved among all fully sequenced orthopox viruses. Sampling number for bootstrap is 1,000; only bootstrap values above 500 are shown (from Guiyun et al., 2006).

after escarification. In the US, several isolates circulated, some of which were obtained from the UK in the first half of the nineteenth century, which were assumed to be derived from Jenner's source material. Obviously there was no way to determine the pedigree of the viruses used. Eventually, the vaccine used in the US as part of the worldwide Small Pox eradication program was called Vaccinia and was manufactured from infected calf skin in the US by Wyeth under the name Dryvax ${ }^{\circledR}$.

Given this state of the art of virology, or rather lack thereof, it is remarkable that vaccination with Vaccinia Virus was as efficacious as it proved to be, ultimately leading to the total eradication of Small Pox from the face of the earth by 1980! The success of this first vaccine led the scientific as well as the lay communities to the erroneous conclusion that producing vaccines was a simple affair and that knowledge of the immune response was unnecessary. This attitude was reinforced by Pasteur (1880) about 100 years after Jenner, and then during the 1950s and 1960s when virologists successfully attenuated many of the viruses responsible for

\section{REFERENCES}

Baxby, D. (1981). Jenner's Smallpox Vaccine. London: Heinemann Educational Books Ltd.

Guiyun, G., Chen, N., Feng, Z., Buller, M., Osborne, J., Harms, T., Damon, I., Upton, C., and Esteban, D. (2006).
Genomic sequence and analysis of a vaccinia virus isolate from a patient with a smallpox vaccinerelated complication. Virol. J. 3,88 .

Jenner, E. (1788). Observations on the natural history of the cuckoo.

the childhood viral exanthems to produce a new catalog of viral vaccines.

It is only now, in the aftermath of the $9 / 11$ tragedies and the anthrax scare in the US, with the specter of bioterrorism threatening to reintroduce Small Pox to the world, that efforts have been undertaken to produce a new vaccine by modern methods. Thus, the Dryvax ${ }^{\circledR}$ vaccine, which is a mixture of viruses, has been grown in tissue culture, and individual viruses have been cloned and characterized genetically and biologically after injection in humans (Nalca and Zumbrun, 2010). A phylogenetic tree of the orthopox viruses is shown in Figure 2 (Guiyun et al., 2006). This tree was generated using an $82 \mathrm{~kb}$ DNA sequence conserved among all fully sequenced orthopox viruses. It's of interest that the Vaccinia Virus strains (VACV) are clustered and distinct from the Cow Pox strains (CPXV), and both are distinct from the Small Pox isolates (VARV). Thus, the vaccine used to eradicate Small Pox is probably not actually the Cow Pox virus discovered by Jenner to protect against the dread disease Small Pox.

Philos. Trans. R. Soc. Lond. 78, 219-212.

Jenner, E. (1798). An Inquiry into the Causes and Effects of Variolae Vaccinae, a Disease Discovered in Some Western Counties of England. London: Sampson Low.
Jenner, E. (1799). Further Observations on the Variolae Vaccinae. London: Sampson Low.

Jenner, E. (1800). A Continuation of Facts and Observations Relative to the Variolae Vaccinae or Cow Pox. London: Sampson Low. 
Jenner, E. (1801). The Origin of the Vaccine Inoculation. London: D.N. Shury.

Koch, R. (1876). Die aetiologie der milzbrand-krankheit, begrundet auf die entwicklungsgeschichte des bacillus antracis. Beitrage zur Biologie der Pflanzen, 2, 277-310.

Nalca, A., and Zumbrun, E. (2010). ACAM2000: the new smallpox vaccine for United States strategic national stockplie. Drug Des. Devel. Ther. 4, 71-79.
Pasteur, L. (1880). Sur les maladies virulentes, et en particulier sur la maladie appelee vulgairement cholera des poules. Comptes Rendus de l' Acad. Sci. 90, 249-248.

Saunders, P. (1982). Edward Jenner The Cheltenham Years 1795-1823. Hanover, NH: University Press of New England.

Studdert, M. (1989). Experimental vaccinia virus infection of horses. Aust. Vet. J. 66, 157-159.

Tulman, E., Delhon, G., Afonso, C., Lu, Z., Zsak, L., Sandybaev, N., Kerembekova, U., Zaitsev, V., Kutish,
G., and Rock, D. (2006). Genome of horsepox virus. J. Virol. 80, 9244-9258.

Conflict of Interest Statement: The author declares that the research was conducted in the absence of any commercial or financial relationships that could be construed as a potential conflict of interest.

Received: 01 May 2011; paper pending published: 20 May 2011; accepted: 02 June 2011; published online: 14 June 2011.
Citation: Smith KA (2011) Edward Jenner and the small pox vaccine. Front. Immun. 2:21. doi: 10.3389/fimmu.2011.00021

This article was submitted to Frontiers in Microbial Immunology, a specialty of Frontiers in Immunology.

Copyright (ㅇ) 2011 Smith. This is an openaccess article subject to a non-exclusive license between the authors and Frontiers Media SA, which permits use, distribution and reproduction in other forums, provided the original authors and source are credited and other Frontiers conditions are complied with. 


\section{ADDENDUM IN REVIEW}

One of the reviewers called to attention the omission from this history of Jenner's contention that the Cow Pox likely originated from an affliction of horses termed "grease," which is an exudative dermatitis of the pastern portion of the horse hooves. Evidently, in eighteenth century England, grease was a common syndrome suffered by horses, especially in the Spring. At the time, commonly male farm laborers tended to the horses, while females looked after the cows. However, males would often participate at milking time, especially when there was a rush. It was commonly held that men who worked with the horses afflicted with grease would become resistant to Small Pox just like the milk maids who contracted Cow Pox. Also, it was thought that cows contracted Cow Pox from the men who also tended the horses, as grease and Cow Pox commonly occurred simultaneously at a farm. Accordingly, Jenner also used material from horses with grease as a source of vaccine, which he found as useful as the material that he took from Cow Pox lesions (Jenner, 1798). This history becomes of interest when one considers the mysterious origin of the viruses Jenner used for vaccination, and those that evolved over the ninteeth and early twentieth centuries. At the time of writing this review, I was unaware that any viruses had been isolated from horses. However, a Horse Pox virus isolated from Mongolian horses in 1976 was recently sequenced (Tulman et al., 2006). Phylogenetic analysis indicated that this Horse Pox virus is more closely related to Vaccinia viruses than Cow Pox viruses. However, while closely related to known Vaccinia-like viruses, this isolate of Horse Pox virus contains additional, potentially ancestral sequences absent in other Vaccinia-like viruses, thereby preventing the conclusion that Vaccinia virus is derived, at least from this Horse Pox Virus. However, it is of interest that experimental infection of horses with Vaccinia Virus produces clinical signs of horse pox (Studdert, 1989). Thus, as more Horse Pox and Vaccinia virus isolates are sequenced and compared, it may become evident that the vaccine used by Jenner and then subsequently circulated worldwide is actually Horse Pox Virus and not Cow Pox Virus. In this regard, given these considerations, one wonders whether many, if not all, poxvirus isolates from different species might be used as cross-protective vaccines. 